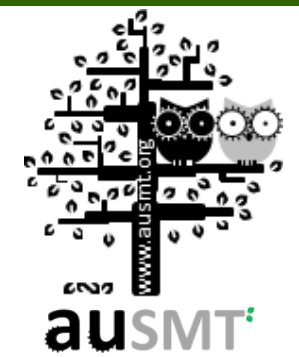

\title{
A high performance, high precision, low cost rapid prototyping and manufacturing technology
}

\section{Vyacheslav R. Shulunov*}

Institute of Physical Materials Science of the Siberian Branch of the Russian Academy of Science, Russia

(Received 8 May 2014; Accepted 9 June 2014; Published on line 1 September 2014)

*Email: asinwt@yandex.ru

DOI: 10.5875 /ausmt.v4i3.718

Abstract: A novel roll powder sintering (RPS) technology is proposed for processing real plastic, ceramic, metal and other 3-D objects $1 \mathrm{~m}^{3}$ (or more) in volume directly from a CAD model within several hours. The breakthrough advantages of the technology are compared to the dominant rapid prototyping and manufacturing (RP\&M) processes that are currently on the market.

Keywords: High performance RP\&M; high precision RP\&M; inexpensive RP\&M

\section{Introduction}

Rapid prototyping techniques have been intensively studied for nearly 20 years[1-4], and the commercial applications are currently dominated by four relatively mature rapid prototyping and manufacturing (RP\&M) processes [5]: stereolithography (SL), selective laser sintering (SLS), fused deposition modeling (FDM) and laminated object manufacturing (LOM). Each of these four processes represents a special class of RP\&M technologies [6-11]. This paper describes a roll powder sintering (RPS) technology that combines the main advantages of these mature RP\&M processes.

Costs, performance and component sizes are very important considerations in RP\&M. In comparison to other RP processes, the outstanding advantages of LOM are its overall low cost $[12,13]$, high building speed, easy post-post processing, the robustness of the manufactured parts, and the fact that it does not require phase changing and does not entail supports or large size parts [14, 15]. Most components can be quickly and inexpensively obtained by following the general principle of the paper lamination RP process [13-15].
Powder technologies cannot be used with LOM, FDM [16] and SL techniques, so it is preferable to have a wide range of RP\&M materials available, though these materials may be less than ideal. Since machine components can be made out of different materials, a range of different powders (ceramic, metal [17-24], plastic etc.) is required. SLS uses a powder [25] but requires a powerful laser and also suffers from thermal distortion [26]. The proposed system, on the other hand, can use any powder material, without the use of a powerful laser, and results in minimal thermal distortion.

SL and SLS requires a 2-D scanning system, and the variable performance of different scanning systems can reduce system accuracy [27] through laser trace distortion errors. Such systems were studied by [28].

The proposed RPS does not suffer from the disadvantages of 2-D scanning systems because the proposed system only uses a laser beam in one dimension.

\section{Proposed system}

\section{Principles and components}

Ideally, the proposed system will combine all the ausMT Vol. 4 No. 3 (2014) 
advantages (accuracy, performance, different materials, low cost, etc.) of mature RP\&M processes. The proposed RPS system is similar to LOM [29], but does not use a heated roller and a moving platform, and to slice up and remove excess material to increase performance.

Figure 1 provides a general illustration of the proposed RPS plant.

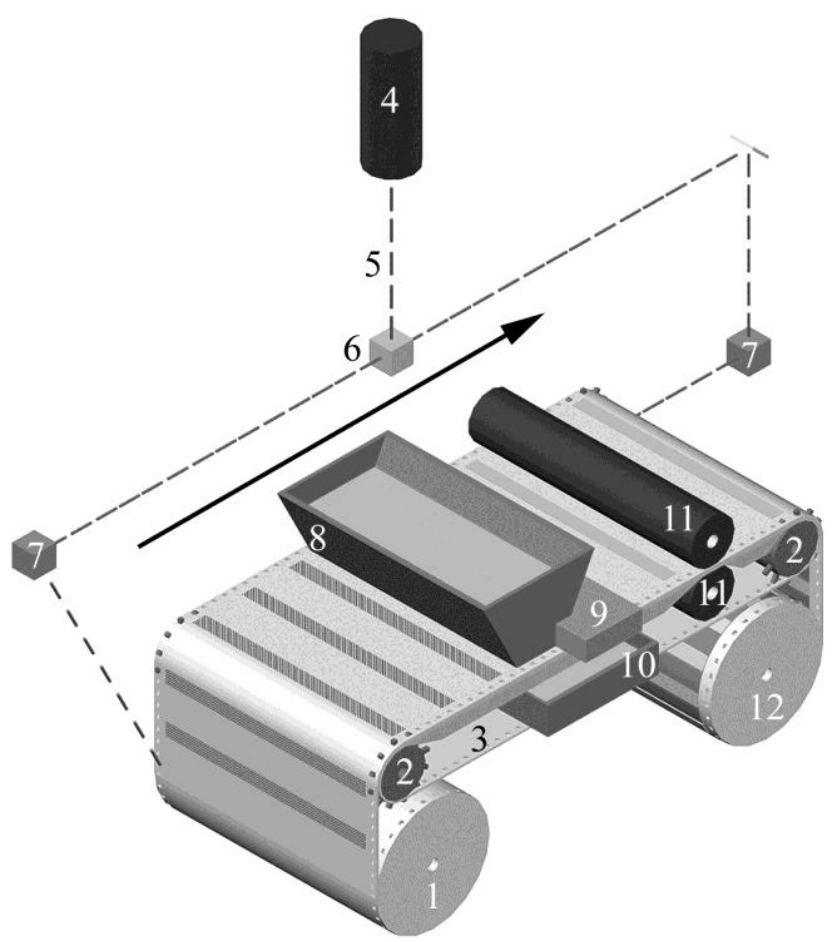

Figure 1. Simplified RPS diagram: 1. Ribbon roll. 2. Extending rollers. 3. Supporting ribbon. 4. Laser. 5. Laser beam. 6. Beam reflector. 7. 1D scanning system. 8. Upper bunker. 9. Excess powder remover. 10. Lower bunker. 11. Pressure rollers. 12. Component roll.

The construction process consists of a thin, inexpensive, easily-dissolved, compressible (at a wide interval) ribbon with perforations along the side to ensure precision. The required production accuracy determines the ribbon's thickness, e.g. 15, 30, $50 \mu \mathrm{m}$ or more.

First, a ribbon roll is rewound in the arrow's direction by extending the rollers (2) and the supporting ribbon (3). If the ribbon speed is similar to the speed of a regular laser printer (40 pages of A4 format per minute), then the processing of a component roll (12) with the ribbon (about $100 \mu \mathrm{m}$ thick and 3 liters in volume) takes about 12 minutes. Using an A2 format ribbon makes it possible to process the component roll at double the volume in the same amount time, thus significantly

Viacheslav Shulunov is a research assistant at the Institute of Physical Materials Science of the Siberian Branch of the Russian Academy of Science. He received his Ph.D. degree in Thermal Physics and Theoretical Heat Engineering in 2002 from the East Siberia State University of Technology and Management. His research interests lie broadly in the area of CAD, with specific focus on additive manufacturing processes, design for manufacturing, feature technology and rapid prototyping \& tooling. increasing the object processing volume at a constant ribbon speed, e.g. about 60 liters per hour (approximately, $1 \mathrm{~m}^{3}$ in 17 hours), using an $\mathrm{AO}$ format ribbon.

\section{Laser perforation}

While the compressible ribbon is being rewound, the laser perforates it in the places where a powder needs to be poured, i.e., where the component will be located (Figure 2(a)).

The laser burns out tiny holes in the ribbon up to $1^{\text {st }}$ extending roller and a supporting ribbon. The holes should be arranged in a checkered fashion (to decrease the area between the neighboring holes) and should be oriented at an acute angle from the vertical ribbon.

If the ribbon is perforated with the resolution of a standard laser printer (i.e., $1200 \mathrm{dpi}$ or more), the diameter of the hole is about $21 \mu \mathrm{m}$ or less.

Due to the inclined perforation, the ribbon becomes similar to the grater (Figure2(b)), and the direction of the holes facilitates the process of powder filling.

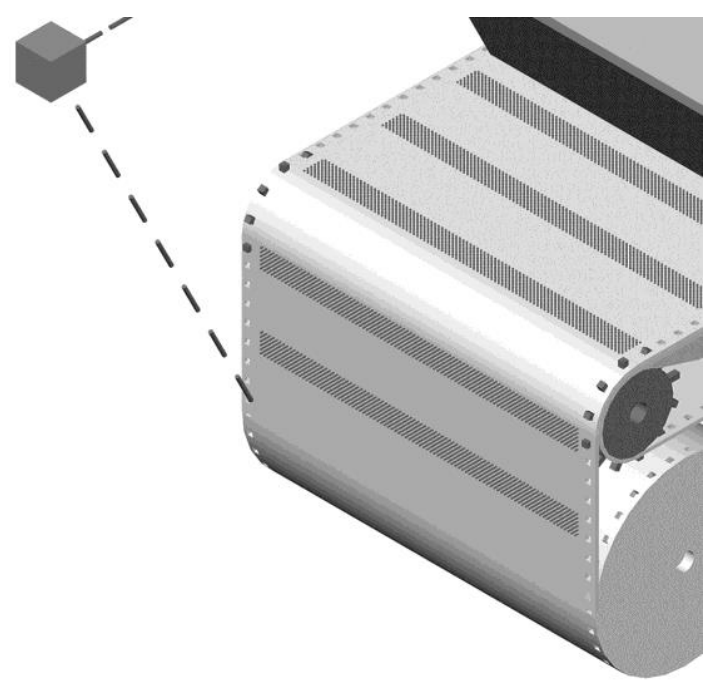

(a)

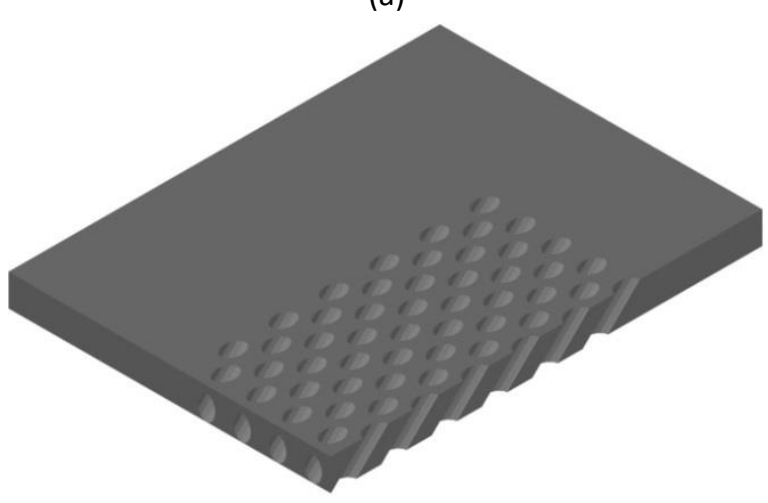

(b)

Figure 2. (a) Tiny inclined laser perforation on ribbon, (b) SW isometric view. 


\section{Ribbon holes filling and flattening out.}

Following laser perforation, the holes are filled with the powder from the upper bunker (1) (Figure 3).

The diameter of the largest powder particle should be at least 3 times smaller than the diameter of the hole. Thus, a resolution of 1200 holes per inch requires powder particles with a diameter of $7 \mu \mathrm{m}$ or less. Using mixed particles of different sizes improves the filling process and connections between neighboring holes.

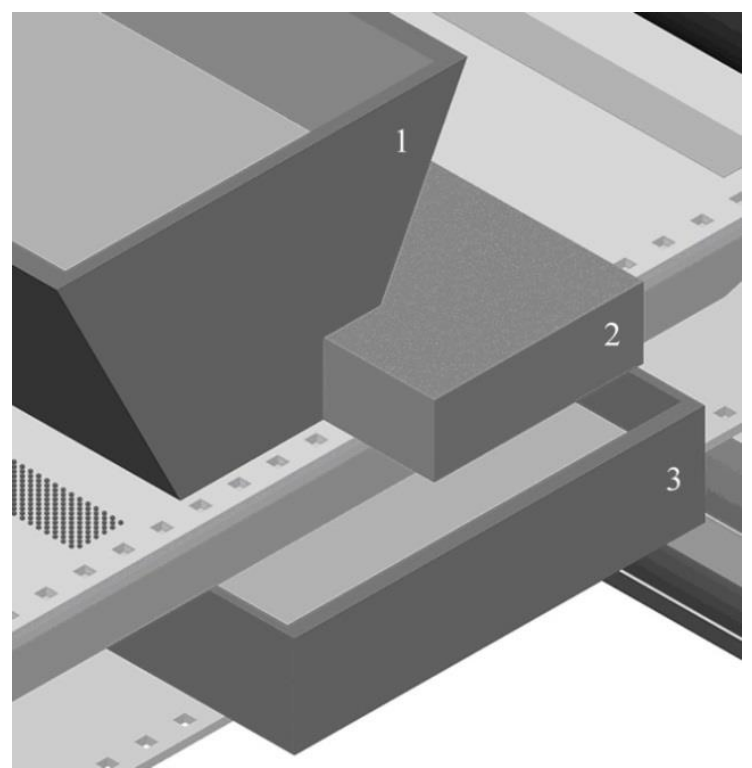

Figure 3. Powder filling ribbon holes: 1. Upper bunker. 2. Excess powder remover. 3. Lower bunker.

Extra particles from the top of the ribbon which are not captured by the holes are removed to the lower bunker (3) by the excess powder remover (2).

Figure 4 shows a piece of ribbon with holes filled by powder particles of different sizes before pressure is applied. The accuracy required for component construction is determined by the ribbon thickness and the size of powder particles.

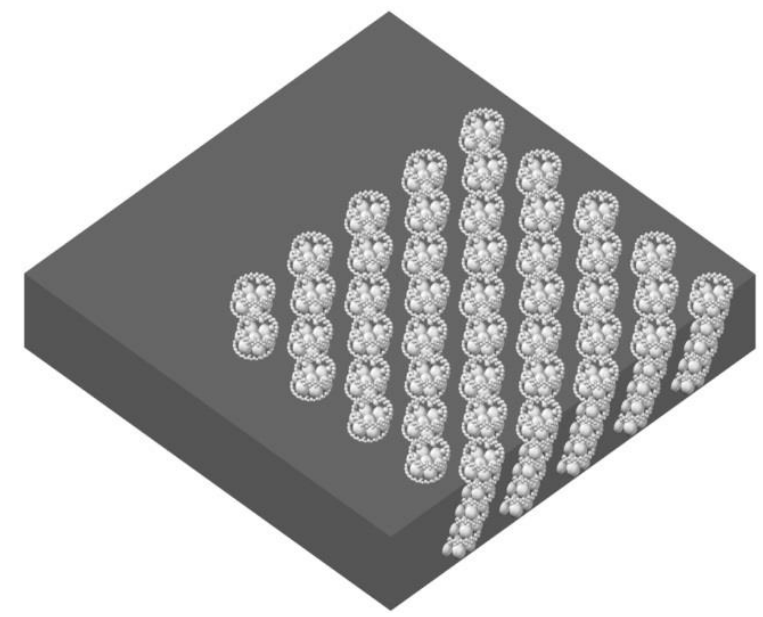

Figure 4. Ribbon with filled holes, SW isometric view.
To improve accuracy and sintering, the filled ribbon is flattened evenly from top to bottom by the upper and lower pressure rollers (Figure 5).

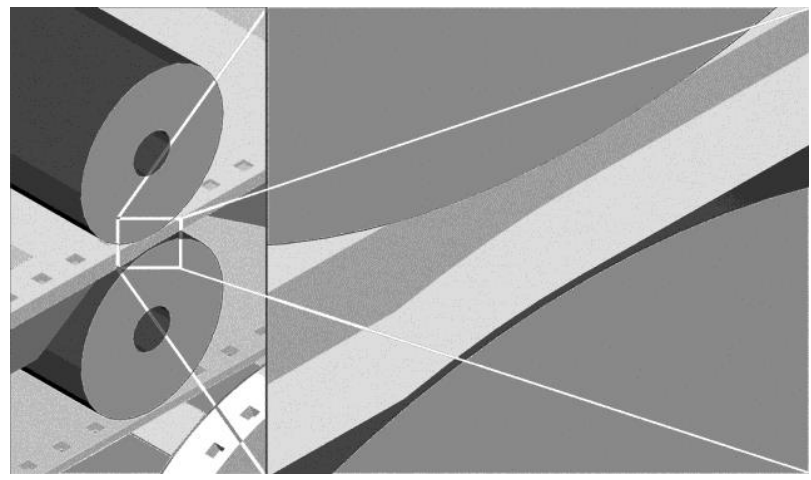

Figure 5. Rollers pressing filled ribbon.

During pressing, the ribbon is compressed to merge the neighboring filled holes as seen in Figure 6. In this case, there are no separate holes, producing a single continuous component.

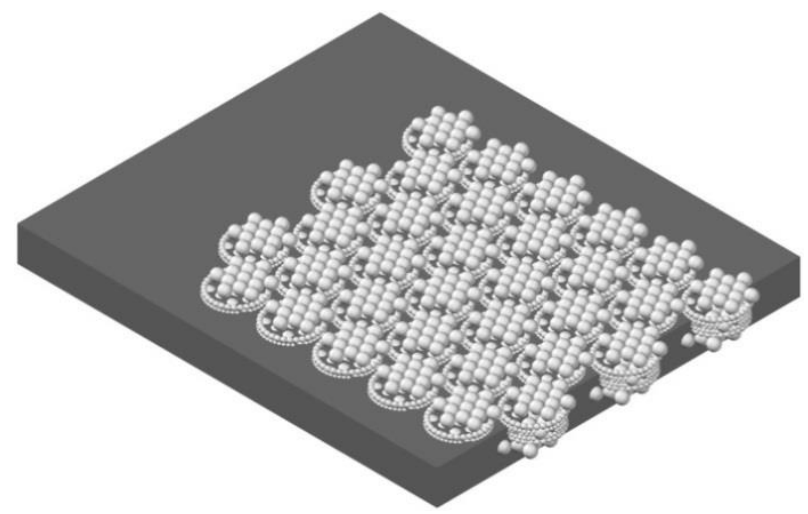

Figure 6. Filled ribbon after pressure, SW isometric view.

Ribbon removal and component sintering.

Once the manufacturing process is complete, the ribbon must be removed. First, empty areas are perforated by a laser behind the $2^{\text {nd }}$ extending roller (Figure 7(a)), burning out larger holes in the ribbon in a checkered pattern with a perpendicular orientation (Figure $7(b)$ ).

When the whole component roll is rewound, it is ready for a sintering plant. Sintering is possible under a wide range of conditions, at different temperatures, pressures, vacuums or gas states (Figure 8).

Finally, the unused bits of a compressible ribbon in cavities and other places can be easily dissolved, e.g., by water (Figure 9). 


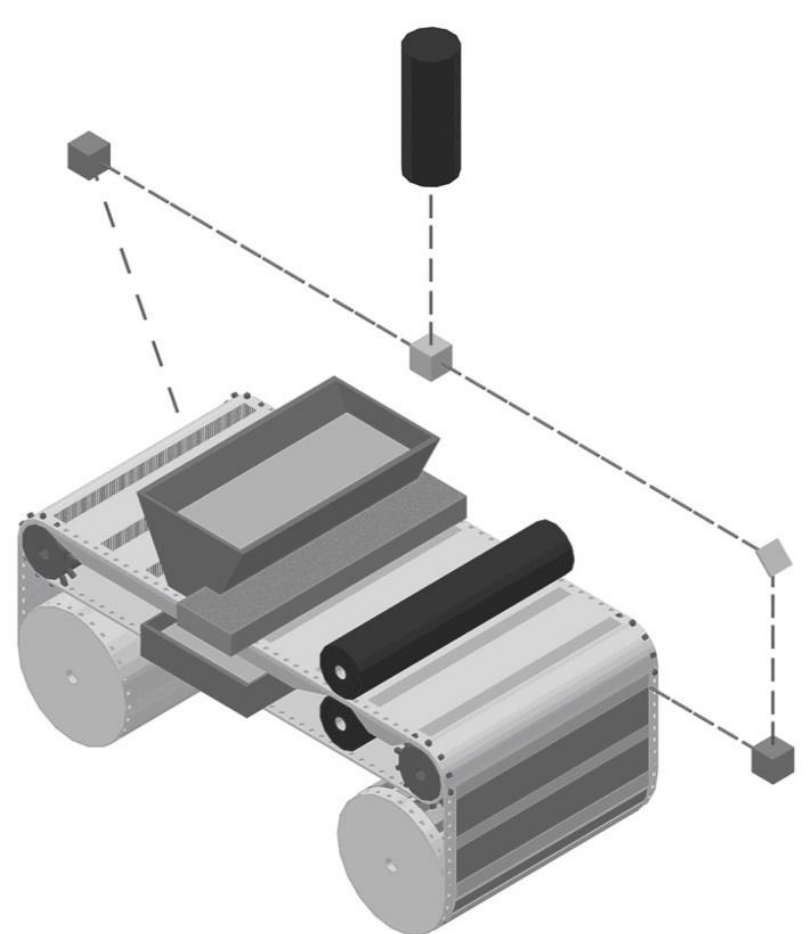

(a)

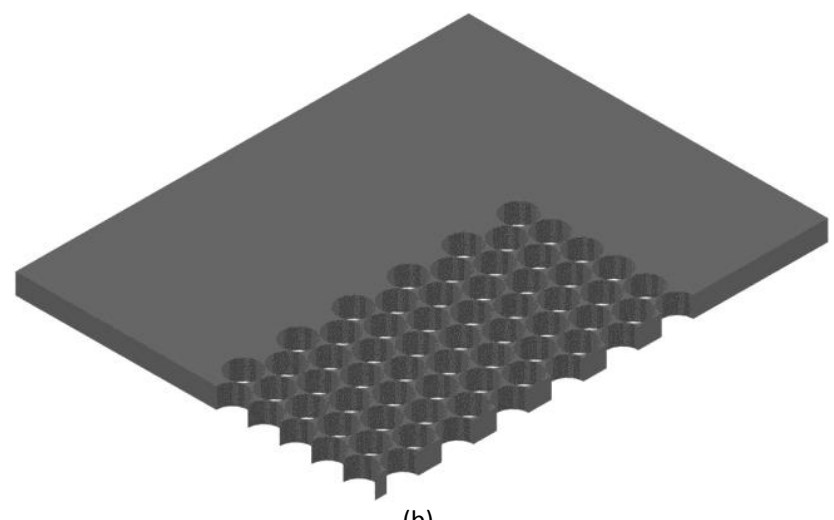

(b)

Figure 7. (a) Laser perforation with larger holes, (b) a piece of ribbon with larger holes, SW isometric view.

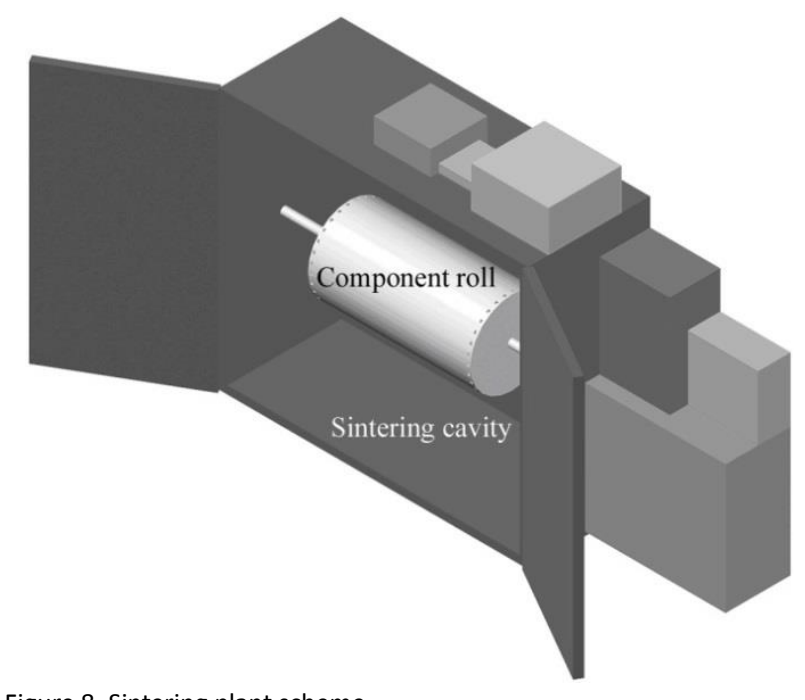

Figure 8. Sintering plant scheme.

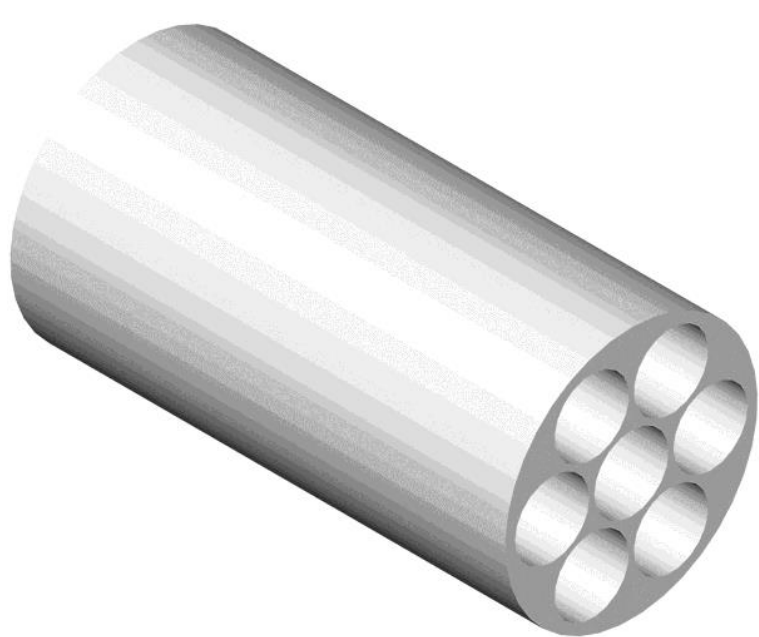

Figure 9. Component following removal of the compressible ribbon.

\section{RPS Modifications.}

Alternatively, a three-layered ribbon can be used (Figure 10). The middle layer is identical to the compressible ribbon, but is already perforated with tiny holes in a checkerboard pattern, at an acute angle. Its top and bottom are coated with a thin, easily-melted and a easily-dissolved layers.

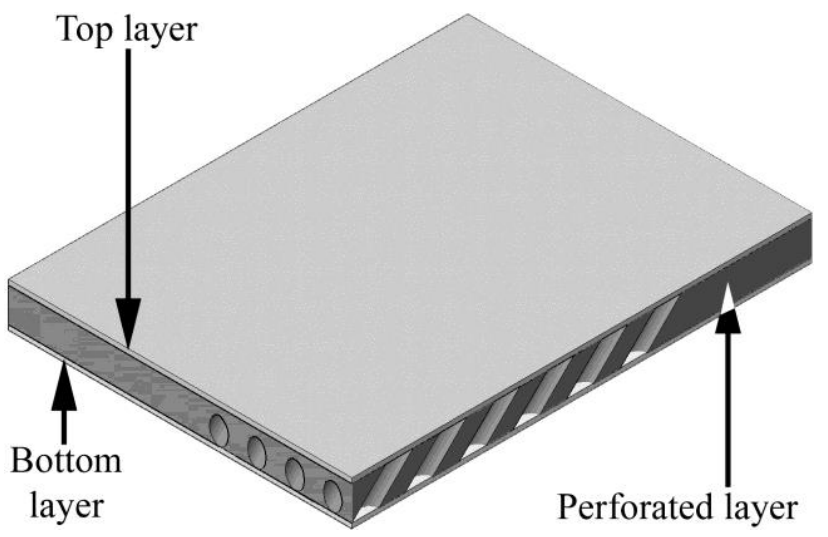

(a)

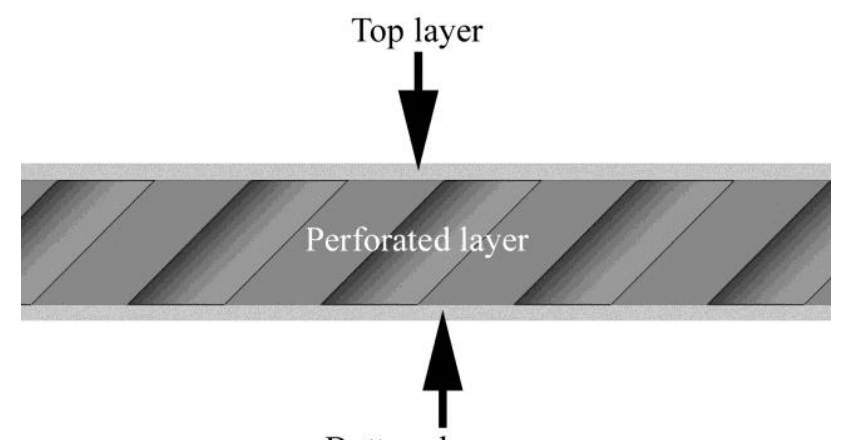

Bottom layer

(b)

Figure 10. Structure of the three-layered ribbon (a) SW isometric view and (b) right view. 
Figure 11 shows a simplified view of a modified RPS model. RPS plant cost is reduced because of the simplified construction and the fact that the top layer of the three-layered ribbon is easily melted and only requires a relatively low-powered laser (3).

In this case, a beam deflector and the second 1-D scanning system are not necessary. A supporting ribbon is also eliminated because its function is now fulfilled by the bottom layer of the three-layered ribbon.

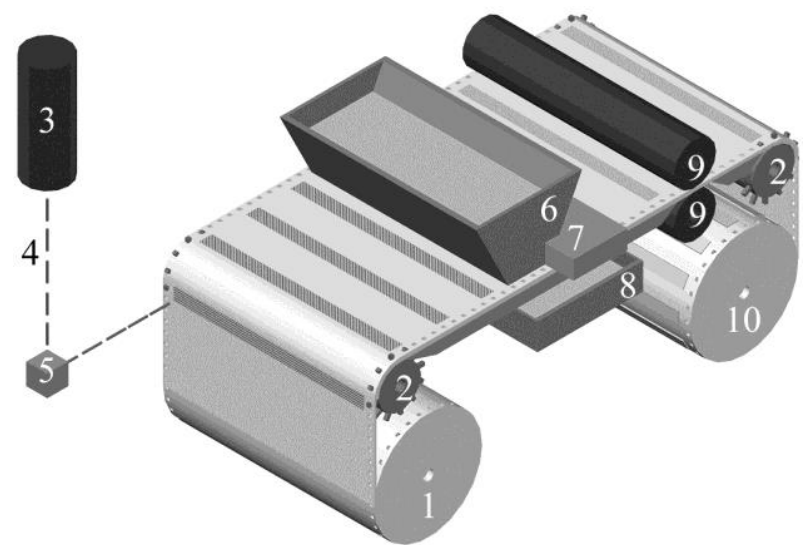

Figure 11. Modified RPS simplified diagram: 1. Ribbon roll. 2. Extending rollers. 3. Laser. 4. Laser beam. 5. 1D scanning system. 6. Upper bunker. 7. Excess powder remover. 8. Lower bunker. 9. Pressure rollers. 10. Component roll.

\section{Conclusion}

This paper describes the improved accuracy, performance, and cost characteristics of a novel RPS process developed to manufacture components from a CAD model. This RPS makes use of commercially-available inexpensive components, reducing costs through the use of a larger laser dot size, thicker building ribbon, smaller particle sizes, while simultaneously improving element accuracy, surface quality, and construction time.

The proposed RPS can manufacture $1 \mathrm{~m}^{3}$ objects in about 17 hours or less. Also, the use of a thin ribbon and 1-D scanning system makes it possible to build a layer tens of microns thick while avoiding 2-D laser trace errors and distortions.

\section{Acknowledgement}

The authors wish to thank Rubin P. Shulunov (East Siberia State University of Technology and Management) for his useful remarks, recommendations and corrections.

\section{References}

[1] E. C. Santos, M. Shiomi, K. Osakada, and T. Laoui, "Rapid manufacturing of metal components by laser forming," International Journal of Machine Tools \& Manufacture, vol. 46, no. 12, pp. 1459-1468, 2006.

doi: 10.1016/i.ijmachtools.2005.09.005

[2] C.K. Chua and K. F. Leong, Rapid prototyping : Principles \& applications in manufacturing. Singapore: John Wiley \& Sons, 1997.

[3] J. Beaman, J. W. Barlow, D. L. Bourell, R. H. Crawford, H. L. Marcus, and K. P. McAlea, Solid freeform fabrication : A new direction in manufacturing : With research and applications in thermal laser processing. Dordrecht; Boston: Kluwer Academic Publishers, 1997.

[4] L. Lu, J. Fuh, and Y. S. Wong, Laser-induced materials and processes for rapid prototyping. Boston: Kluwer Academic Publishers, 2001.

[5] F. Xu, Y. S. Wong, and H. T. Loh, "Toward generic models for comparative evaluation and process selection in rapid prototyping and manufacturing," Journal of Manufacturing Systems, vol. 19, no. 5, pp. 283-296, 2001. doi: 10.1016/S0278-6125(01)89001-4

[6] P. F. Jacobs, Rapid prototyping \& manufacturing : Fundamentals of stereolithography. Dearborn MI: Society of Manufacturing Engineers in cooperation with the Computer and Automated Systems Association of SME, 1992.

[7] P. F. Jacobs, Stereolithography and other $r p \& m$ technologies : From rapid prototyping to rapid tooling. Dearborn, Mich.; New York: Society of Manufacturing Engineers in cooperation with the Rapid Prototyping Association of SME ; ASME Press, 1996.

[8] F. B. Prinz et al., JTEC/WTEC panel on rapid prototyping in europe and japan. Baltimore, Md.: Rapid Prototyping Association of the Society of Manufacturing Engineers in cooperation with International Technology Research Institute, 1997. Available:

http://www.wtec.org/loyola/rp/toc.htm

[9] DTM Corporation, "The sinterstation 2000 system sls guide to materials - optimizing \& understanding the process,"

[10] DTM Corporation, "Sinterstation 2000 system selective laser sintering-users' guide,"

[11] C. K. Chua and K. F. Leong, Rapid prototyping : Principles \& applications in manufacturing. Singapore: John Wiley \& Sons, 1997.

[12] G. Yu, Y. Ding, D. Li, and Y. Tang, "A low cost cutter-based paper lamination rapid prototyping system," International Journal of Machine Tools and Manufacture, vol. 43, no. 11, pp. 1079-1086, 2003.

doi: 10.1016/S0890-6955(03)00125-1 
[13] Y. S. Shi, J. H. Muo, S. H. Huang, and Z. D. Zhou, "Convenient rapid prototyping systems and selection principle," Metalforming Machinery, vol. 02, pp. 1-6, 2001.

[14] B. Mueller and D. Kochan, "Laminated object manufacturing for rapid tooling and patternmaking in foundry industry," Computers in Industry, vol. 39, no. 1, pp. 47-53, 1999. doi: $10.1016 /$ S0166-3615(98)00127-4

[15] D. T. Pham and R. S. Gault, "A comparison of rapid prototyping technologies," International Journal of Machine Tools and Manufacture, vol. 38, no. 10-11, pp. 1257-1287, 1998. doi: 10.1016/S0890-6955(97)00137-5

[16] O. Kerbrat, P. Mognol, J.-Y. Hasco, and \#235, "A new $\mathrm{dfm}$ approach to combine machining and additive manufacturing," Comput. Ind., vol. 62, no. 7, pp. 684-692, 2011.

doi: $10.1016 /$ i.compind.2011.04.003

[17] B. Sundman, I. Ohnuma, N. Dupin, U. R. Kattner, and S. G. Fries, "An assessment of the entire Al-Fe system including d03 ordering," Acta Materialia, vol. 57, no. 10, pp. 2896-2908, 2009. doi: 10.1016/j.actamat.2009.02.046

[18] D. L. Joslin, D. S. Easton, C. T. Liu, S. S. Babu, and S. A. David, "Processing of fe3al and feal alloys by reaction synthesis," Intermetallics, vol. 3, no. 6, pp. 467-481, 1995. doi: 10.1016/0966-9795(95)00006-K

[19] D. L. Joslin, D. S. Easton, C. T. Liu, and S. A. David, "Reaction synthesis of fe al alloys," Materials Science and Engineering: A, vol. 192-193, Part 2, pp. 544-548, 1995. doi: $10.1016 / 0921-5093(94) 03272-6$

[20] K. S. Yun, J. H. Lee, and C. W. Won, "Effect of current application methods on the preparation of fe-al intermetallic compounds by field-activated combustion synthesis," Materials Research Bulletin, vol. 35, no. 10, pp. 1709-1716, 2000.

doi: $10.1016 / \mathrm{S} 0025-5408(00) 00364-0$
[21] S. Kobayashi and T. Yakou, "Control of intermetallic compound layers at interface between steel and aluminum by diffusion-treatment," Materials Science and Engineering: $A$, vol. 338, no. 1-2, pp. 44-53, 2002.

doi: 10.1016/S0921-5093(02)00053-9

[22] W. Deqing, "Phase evolution of an aluminized steel by oxidation treatment," Applied Surface Science, vol. 254, no. 10, pp. 3026-3032, 2008. doi: 10.1016/i.apsusc.2007.10.059

[23] P. Matysik, S. Jozwiak, and T. Czujko, "The kinetics of non-isothermal iron and aluminum powder mixtures sintering in protective atmosphere," Journal of Alloys and Compounds, vol. 549, pp. 92-99, 2013. doi: 10.1016/j.jallcom.2012.08.129

[24] Nagahanumaiah, K. Subburaj, and B. Ravi, "Computer aided rapid tooling process selection and manufacturability evaluation for injection mold development," Computers in Industry, vol. 59, no. 2-3, pp. 262-276, 2008. doi: 10.1016/j.compind.2007.06.021

[25] D. Corporation, "A platform that supports the entire design process," 1996.

[26] F. Klocke, T. Celiker, and Y.-A. Song, "Rapid metal tooling," Rapid Prototyping Journal, vol. 3, no. 1, pp. 32-42, 1995. doi: $10.1108 / 13552549510094250$

[27] S. Gmbh, "Installation and operation, pc real time control board rtc2, for scan head and laser control in time," 1998.

[28] Y. Tang, H. T. Loh, J. Y. H. Fuh, Y. S. Wong, L. Lu, Y. Ning, and $X$. Wang, "Accuracy analysis and improvement for direct laser sintering," Innovation in Manufacturing Systems and Technology (IMST), vol. 01, 2004.

[29] M. N. Diamond, E. Dvorskiy, M. Feygin, and A. Shkolnik, "Laminated object manufacturing," US Patent 5730817A, 1998. 